\title{
Mediating Effects of Parental Stress on Harsh Parenting and Parent-Child Relationship during Coronavirus (COVID-19) Pandemic in Singapore
}

\author{
Gerard Chung $^{1}\left[\right.$ D Paul Lanier ${ }^{1} \cdot$ Peace Yuh Ju Wong ${ }^{2}$ \\ Published online: 2 September 2020 \\ (C) Springer Science+Business Media, LLC, part of Springer Nature 2020
}

\begin{abstract}
Because of the Coronavirus (COVID-19) pandemic, "Circuit-breaker" safety distancing was implemented in Singapore from April to May 2020. Schools and workplaces were closed and parents had to balance telecommuting with parenting responsibilities. Coupled with the high degree of economic uncertainty and reduced social support, these circumstances are hypothesized to increase parenting stress. Based on the Parental Stress Model, this study aims to understand how parents' perceived impact of COVID-19 increased harsh parenting and reduced parent-child relationship closeness through the mediating effects of parenting stress. We collected data from 258 parents living in Singapore using online surveys disseminated through Facebook and community organizations. Our predictor was the perceived impact of COVID-19. Parental stress (mediator) was measured with the Parental Stress Scale. Two outcomes were used: parent-child relationship closeness and harsh parenting (spanking, yelling). Using mediation analysis in the SEM framework, we tested the indirect effects using bias-corrected bootstrap confidence intervals. Our results indicated that parenting stress was a significant mediator in the relationship between the perceived impact of COVID-19 and (a) parent-child closeness (indirect effect $=-.30$, Bootstrap 99\% CI[-.59, -.11]) and (b) harsh parenting (indirect effect $=.58$, Bootstrap $99 \% \mathrm{CI}[.25, .94]$ ). The impact of COVID-19 and stay-home orders can increase parenting stress. This, in turn, has a negative impact on parenting by affecting parents' relationship with their children and increasing the use of harsh parenting. Given that these are risk factors for potential child abuse, supporting parents and mitigating the impact of COVID-19 are important.
\end{abstract}

Keywords Coronavirus (COVID-19) $\cdot$ Singapore $\cdot$ Parental stress $\cdot$ Harsh parenting $\cdot$ Relationship

\section{Introduction}

The coronavirus (SARS-CoV-2) has caused a pandemic of acute respiratory syndrome (COVID-19) with far-reaching global impacts. In January 2020, the World Health Organization (WHO) declared the pandemic a "public health emergency of international concern" (WHO 2020). As of May 15, 2020, more than 4 million people worldwide had been

Gerard Chung

gcsk1982@live.unc.edu

1 School of Social Work, University of North Carolina at Chapel Hill, Tate-Turner-Kuralt Building, 325 Pittsboro Street CB\# 3550, Chapel Hill, NC 27599-3550, USA

2 Department of Social Work, National University of Singapore, BLK AS3 Level 4, 3 Arts Link Singapore, 117570 Singapore, Singapore infected with COVID-19, resulting in 282,309 deaths as reported by the New York Times (2020) drawing data from various sources including WHO. Governments' responses across the world have ranged from physical distancing to partial or complete lockdowns of their populations to slow the rate of transmission of the highly infectious disease. With the closure of businesses and workplaces, the pandemic had a significant financial impact on people and the global economy. The International Labor Organization (ILO) estimated that the COVID-19 pandemic could lead to 24.7 million jobs lost worldwide - a worst-case scenario for global unemployment (ILO 2020). The daily lives of families and children have also been transformed, as many countries have closed schools, parks, and child-care facilities. The United Nations' Educational, Scientific, and Cultural Organization estimates that 1.38 billion children are out of school or child care and do not have access to group and outdoor activities, team sports, or playgrounds as a result of the pandemic (cited in Cluver et al. 2020). 
Although physical distancing and lockdown measures help reduce community-based transmissions, they can also be detrimental to family life (Cluver et al. 2020). Many parents are attempting to work remotely from home while caring for children. Parents with school-going children also face new demands of home-based schooling. These demands are even greater for parents who must additionally care for older adults or children with chronic behavioral problems, special needs, or disabilities. Given the high degree of economic uncertainty facing many families, parents are often caring for their children under stressful conditions with limited resources. Coyne et al. (2020) described the stressful "collision of roles, responsibilities, and expectations" (i.e., as a parent, spouse, employee, employer, caregiver, teacher) experienced by parents during this pandemic as they face great uncertainty about the future. As parental stress increases, researchers have warned about the increased risk of family violence and child abuse during this period when families remain at home with reduced community contact and external social support (Brown et al. 2020; Campbell 2020). Child protection services (CPS) across countries impacted by COVID-19 are reporting an increase in cases and referrals of child abuse (Agrawal 2020; Channel News Asia [CNA], 2020a).

\section{"Circuit-Breaker" and COVID-19 in Singapore}

In Singapore, the first COVID-19 case was confirmed in January 2020. By May 14, 2020, Singapore had more than 26,000 cases among its population of 5.7 million people. Because of the increasing rate of transmission over March, on April 3, 2020 the Singapore government responded by implementing a month-long nationwide safety distancing measure termed "Circuit-breaker" (CNA 2020b). Under Circuit-breaker, schools, child-care services, student care centers, businesses, and workplaces were closed and people were encouraged to stay at home. As a result, many parents had to work from home and provide full home-based learning to their children. Subsequently, on April 21, 2020, the Singaporean government imposed stricter safety distancing measures, including closing more businesses, implementing screening measures for people accessing high-transmission areas (e.g., wet markets), and restricting social gatherings in public places (Mohan 2020). Eventually, Circuit-breaker was extended for a second month in order to further reduce transmission rates. Although this extension was expedient from a public health point of view, for parents it meant prolonging their telecommuting, caregiving, and home-based learning responsibilities without respite. Moreover, based on local news reporting, the extension has disproportionately burdened those parents who were already overwhelmed by financial and familial responsibilities (Yip and Smalley 2020; Zhuo and Tai 2020).
Indeed, many families are experiencing financial difficulties because of the impact of the pandemic and Circuit-breaker measures on Singapore's economy, with job closures and reduced wages affecting many workers (Tang 2020), especially ad-hoc and self-employed workers (Singapore Social, Lifestyle and Infection Networks Group 2020). Circuitbreaker has disrupted social connections and parents' ability to access support from family members as well as their extended communities in Singapore (CNA 2020c), similar in other countries where social distancing measures are also implemented (Weems et al. 2020). Across countries, parents who previously depended on families, churches, schools, and neighbors for caregiving support, financial help, and social interactions now find themselves cut off from these support systems (Weems et al. 2020). In addition to reducing families' access to external supports, this social isolation can have mental health consequences. A recent review of studies on quarantine have found that loneliness, depression, and other psychological health impacts are among the most common outcomes of quarantining and other physical distancing measures (Brooks et al. 2020).

Given that COVID-19 and Circuit-breaker are significantly impacting many parents' finances, access to resources, and psychological health, the present study assesses how pandemic conditions are affecting parents in their role of parenting. Previous studies have shown that large-scale events such as economic recessions, wars, and natural disasters can be detrimental to parenting. For instance, during the Great Recession of 2008, a large decline in consumer confidence was associated with increased levels of harsh parenting and spanking among parents in the United States (Brooks-Gunn et al. 2013). In their meta-analysis of studies looking at the effects of war exposure on parenting, Eltanamly et al. (2019) found that war-exposed parents showed less warmth and more harshness toward their children. Notably, they also found that the quality of parenting was an important contributing factor to the level of adjustment and recovery among the children who had experienced the effects of war. In light of these findings and the current difficulties experienced by Singaporean parents during the COVID-19 pandemic, our study assesses the pandemic's effects on the parenting behaviors of these parents.

\section{Parental Stress}

Parenting contributes in important ways to the course and outcome of child development (National Academies of Sciences 2016) and parental stress is one important area of focus in parenting research. In Abidin (1992)'s Parental Stress Model, parental stress is a key determinant of parenting practices, especially dysfunctional parenting. Based on Deater-Deckard (1998), parental stress has been defined as a psychological reaction when parents experience parental 
demands that are inconsistent with expectations (expectations of self or from others) or when parents do not have the resources to meet these demands (as cited in Holly et al. 2019). Parental stress is conceptually distinct from other forms of stress that a parent might experience (e.g., marital or work stress), although they are often associated (Holly et al. 2019). The Parental Stress Model's definition of parental stress also aligns with the definition of parental stress proposed by Lazarus and Folkman (1984), which posits that this stress arises from a parent's appraisal of environmental stressors or demands associated with their parenting role. In the Parental Stress Model (Abidin 1992), environment and life events are included as potential stressors of the parenting role. Thus, in the current study, we hypothesized that in the context of COVID-19 and Circuit-breaker regulations, parents who perceived a higher impact of COVID-19 would experience higher levels of parental stress.

\section{Effects of Parental Stress on Parenting}

The second key part of our study examined associations between parental stress and subsequent parenting outcomes. Existing studies indicate that higher levels of parental stress are associated with poorer parenting-related outcomes such as harsh parenting practices and poor parent-child relationships. Deater-Deckard (1998)'s review of existing studies found that parents with higher levels of parental stress were more likely to be authoritarian, harsh, and negative in their parenting and less responsive and close with their children. Newer studies conducted in the United States found that higher parental stress was associated with fathers and mothers' higher use of corporal punishment (Jackson and Choi 2018) and more negative mother-child interactions (Crnic et al. 2005). Among Asian studies, parental stress was related with Mainland Chinese fathers' and mothers' use of corporal punishment and psychological aggression on preschool-aged children (Liu and Wang 2015) and lower brain-to-brain synchrony between Singaporean mothers and their children, indicating lesser parental sensitivity and parent-child co-regulation (Azhari et al. 2019). Collectively, these studies indicate that parental stress is related to a wide range of negative parenting outcomes. Our study examined the effects of parental stress on two parenting outcomes: harsh parenting and parent-child relationship closeness.

\section{Harsh Parenting}

Harsh parenting includes coercive, aggressive, and emotionally charged disciplinary practices such as caning, spanking, yelling, or shouting at children (Chang et al. 2003). Given its high coerciveness and negative emotionality, several studies have found that harsh parenting has a direct and negative effect on children's subsequent developmental outcomes, including internalizing and externalizing symptoms (Gershoff et al. 2018; Pinquart 2017).
Harsh parenting has also been identified as a risk factor for child abuse and neglect (Lee et al. 2014). In their latent class analysis of cases investigated by the CPS in Singapore for child maltreatment, Chng et al. (2018) found a group of cases, distinct from other cases, that is characterized by (a) higher levels of harsh parenting and (b) the highest percentage of cases reported for physical and emotional child abuse. The current prevalence of corporal punishment among Singaporean parents is uncertain due to the lack of any prevalence studies in the last decade. A 1996 study by Tong et al. found that among a random sample of 401 Singaporeans living in public housing, a majority of respondents (72\%) felt that caning children was sometimes or always acceptable as a disciplinary practice. Although corporal punishment is still acceptable to some parents in Singapore, it carries a high risk of resulting in injury and child abuse if used over a prolonged period or to an extreme degree. Furthermore, corporal punishment may not be effective in managing children's behaviors, and in fact encourage negative behaviors (Gershoff et al. 2018). For instance, Sim and Ong (2005) found that Singaporean parents' use of slapping and caning was subsequently associated with higher levels of aggression among their preschool-aged children.

\section{Parent-Child Relationship}

Our study also focused on parent-child relationships because considerable evidence suggests that parent-child relationships can affect child well-being (Pinquart 2017). Parent-child relationships characterized by warmth, closeness, and emotional openness have also been found to be a protective factor in helping children recover from large-scale traumatic events (e.g., the terrorist attack in the U.S. on September 11, 2001; Lutz et al. 2007), war (Eltanamly et al. 2019), and natural disasters (e.g., Hurricane Katrina; Salloum and Lewis 2010). We focused on parents' perceptions of their relationships with their children since parents' attitudes or perceptions may change across time being shaped by stressors or interactions with their environment (Driscoll and Pianta 2011).

\section{Aims and Research Hypotheses}

In the Parental Stress Model (Abidin 1992), the influence of environmental stressors on parenting outcomes such as harsh parenting and parent-child relationship is hypothesized to be mediated by parental stress. For example, Jackson and Choi (2018) found that economic hardships increased parental stress among mothers, which in turn increased mothers' use of harsh parenting behaviors. Similarly, in the current study, contextual changes wrought by COVID-19 and Circuitbreaker measures were conceptualized to affect parents and their parenting behaviors through the pathway of parental stress (see Fig. 1). We recognized that there are other 
pathways through alternative mediators such as marital stress or family dysfunction (we address this in our study limitations). However, this study only examined the impact of COVID-19 through the mediating effects of parental stress on parenting outcomes, as informed by the 3-term model linking parental cognitions to parenting practices and children outcomes (Bornstein et al. 2018). As shown in Fig. 1, our research hypotheses were:

(a) Parents who perceive a higher impact of COVID-19 will report higher parental stress levels,

(b) Higher parental stress will be associated with greater increases in the use of parent-reported harsh parenting and decreases in these parents' perceived closeness with their child,

(c) Parental stress will mediate the relationship between parents' perceptions of a higher impact of COVID-19 and their negative parenting outcomes.

The current study intends to yield better understandings of the effects of COVID-19 on parents and their parenting. COVID-19 and social distancing measures like Circuitbreaker are unprecedented in Singapore and many other countries. While curbing the virus's transmission is the priority of governments' responses, these responses should also consider the downstream collateral effects on families that need help and support - and perhaps more so under quarantining and social distancing conditions.

\section{Method}

\section{Data and Sample}

We analyzed data from an online survey that we created and disseminated to parents in Singapore from April 22, 2020 to May 5, 2020. To be eligible for survey participation, respondents had to be at least 18 years old (a person below age 18 is considered marriage of a minor in Singapore), currently living in Singapore with at least one child at most 12 years old, and be Singaporean citizens or permanent residents. We focused on young children because schools, infantand child- care facilities, and student care services were ordered to close during the Circuit-breaker significantly affecting parents with children from this age group. Only one respondent from each household was requested to complete the survey so that our study did not include multiple respondents from the same family. We disseminated the online survey using a website link hosted on the Qualtrics server. We reached potential respondents via advertisements on Facebook with a link to the online survey. We engaged family-related community organizations (e.g., Family Central) and parenting-related online groups (e.g. parenting support groups) that helped to post the advertisements on their Facebook websites. We also approached community organizations (e.g., Centre for Fathering) associated with families and parenting in Singapore to help disseminate the online survey (e.g., emails) to their own database of subscribers We chose these methods to disseminate the surveys because these organizations or groups provide information and services that are open to all parents in Singapore. This helps us to widely recruit participants to meet our broad inclusion criteria.

In total, 313 respondents started the survey. Among these respondents, 38 did not complete the survey and seven did not meet the eligibility criteria to participate in the survey (i.e., 45 excluded in total). For the current study, we excluded (a) parents who were not biological, adoptive, or step-parents of the children and (b) parents who were not married because this size of this group within our sample was small (i.e., four excluded in total). We then excluded six additional respondents who had missing responses on the outcome variables in this study. This left us with an analytical sample of 258 respondents.

The study team provided detailed explanations of the study and obtained participant consent from all respondents. This study has been approved by the Institutional Review Board
Fig. 1 Conceptual Model of the Impact of COVID-19 on Parenting Outcomes Through the Mediating Effects of Parenting Stress. Note $:+-$ effect $=$ positive or negative effect; $\mathrm{A}-\mathrm{E}=$ paths

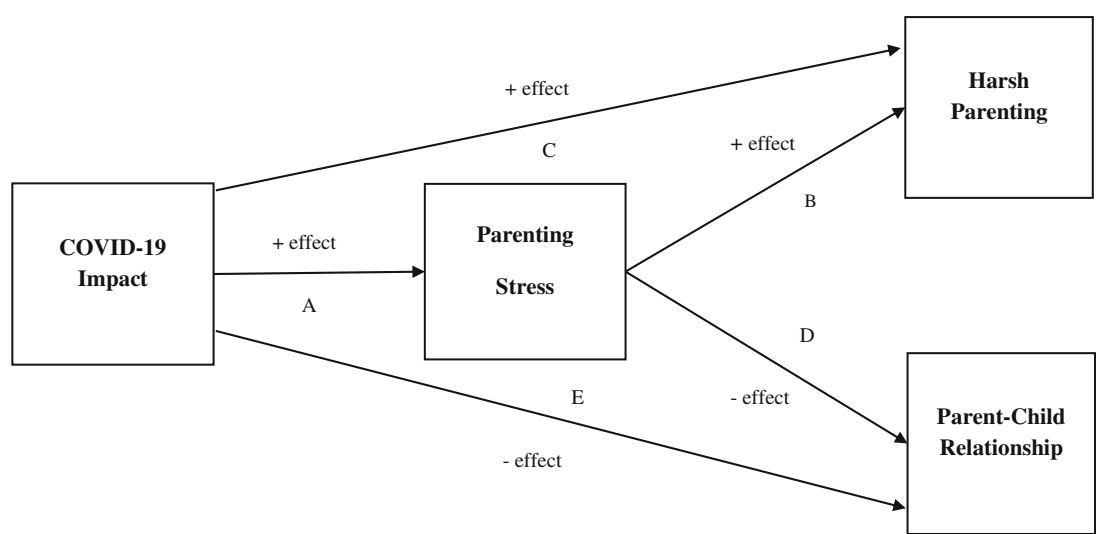


(IRB) at the University of North Carolina at Chapel Hill with IRB number 20-1071. No incentives or compensations were provided to respondents for participating in the survey.

\section{Measures}

The survey consisted of 50 questions and took about $12 \mathrm{~min}$ for the respondents to complete. Survey questions were related to parenting, the impact of COVID-19, and demographic information. Descriptive statistics of study variables are in Table 1.

Coronavirus Impacts Questionnaire (CIQ) The CIQ was developed as one of several social-psychology-relevant questionnaires to measure how people in the United States have been impacted by COVID-19 and social distancing (Conway et al. 2020). In Conway et al. (2020)'s validation of CIQ, confirmatory factor analysis indicated an excellent 3-factor structure for the 9-item version of CIQ. The scale had good face validity and had strong internal reliability within each factor ( $\alpha$ scores ranged from .76 to .93 ).

The three factors of the CIQ are (a) financial impact, (b) resource impact, and (c) psychological impact. Though the CIQ was developed for use in the United States and has not been validated for use in Singapore, we judged it to have content and cross-cultural validity based on its scale items and conceptualization. As earlier discussed, people in Singapore are experiencing the impact of the Circuit-breaker on their psychological health, employment and finances, and access to resources. Examples of items from each of the factors are "The Coronavirus (COVID-19) has impacted me negatively from a financial point of view" (financial impact), "I have had a hard time getting needed resources (food, medicine) due to the Coronavirus (COVID-19)" (resource impact), and "The Coronavirus (COVID-19) outbreak has impacted my psychological health negatively" (psychological impact). Respondents responded to these statements on a 4-point Likert scale ranging from $1=N o t$ true of me at all to $4=$ Very true of me.

In this study, we used the shortened 6-item version of the CIQ created by Conway et al. (2020) because the shortened version has similar psychometrics characteristics to the longer version and would keep the length of the survey short for survey administration. The shortened version contains two items from each of the three factors (i.e., financial, resource, and psychological impact). The Cronbach $\alpha$ for this study was .75. A composite score was created by averaging the score across the six items $(M=2.01, S D=.61)$, with higher scores indicating that the respondent had experienced a greater overall impact on their life due to the pandemic.

Parental Stress Scale (PSS) The PSS measures an individual's perceptions and feelings of stress directly associated with
Table 1 Sample Characteristics and Descriptive Statistics of Study Variables $(n=258)$

\begin{tabular}{|c|c|c|c|c|c|}
\hline & $N$ & $\%$ & $M$ & $S D$ & Range \\
\hline \multicolumn{6}{|l|}{ Parent (natural/adoptive/stepparent) } \\
\hline Mothers & 165 & $64 \%$ & & & \\
\hline Fathers & 93 & $36 \%$ & & & \\
\hline \multicolumn{6}{|l|}{ Parent Race } \\
\hline Chinese & 212 & $82 \%$ & & & \\
\hline Malay & 22 & $9 \%$ & & & \\
\hline Indian & 11 & $4 \%$ & & & \\
\hline More than one race/Others & 13 & $5 \%$ & & & \\
\hline \multicolumn{6}{|l|}{ Parent Age (in years) } \\
\hline $26-30$ & 13 & $5 \%$ & & & \\
\hline $31-35$ & 77 & $30 \%$ & & & \\
\hline $36-40$ & 83 & $32 \%$ & & & \\
\hline $41-45$ & 48 & $19 \%$ & & & \\
\hline $46-50$ & 31 & $12 \%$ & & & \\
\hline $51-55$ & 6 & $2 \%$ & & & \\
\hline \multicolumn{6}{|l|}{ Parent Education } \\
\hline Non-University & 38 & $15 \%$ & & & \\
\hline University & 220 & $85 \%$ & & & \\
\hline \multicolumn{6}{|l|}{ Parent Employment } \\
\hline Stay-at-home parent & 33 & $13 \%$ & & & \\
\hline Employed (full) & 188 & $73 \%$ & & & \\
\hline Employed (temporary/casual) & 15 & $6 \%$ & & & \\
\hline Unemployed (would like to work) & 8 & $3 \%$ & & & \\
\hline Others/Retired/Students & 14 & $5 \%$ & & & \\
\hline \multicolumn{6}{|c|}{ Monthly Household Income (Singapore \$) } \\
\hline$<\$ 1900$ & 10 & $4 \%$ & & & \\
\hline$\$ 1901-\$ 3500$ & 13 & $5 \%$ & & & \\
\hline$\$ 3501-\$ 5000$ & 30 & $12 \%$ & & & \\
\hline$\$ 5001-\$ 8000$ & 56 & $22 \%$ & & & \\
\hline$>\$ 8000$ & 149 & $58 \%$ & & & \\
\hline \multicolumn{6}{|l|}{ Youngest Child Age (in years) } \\
\hline $0-1$ & 63 & $24 \%$ & & & \\
\hline $2-3$ & 54 & $21 \%$ & & & \\
\hline $4-5$ & 47 & $18 \%$ & & & \\
\hline $6-7$ & 31 & $12 \%$ & & & \\
\hline $8-9$ & 33 & $13 \%$ & & & \\
\hline $10-12$ & 30 & $12 \%$ & & & \\
\hline \multicolumn{6}{|c|}{ \# of children at home (age 12 or younger) } \\
\hline 1 & 119 & $46 \%$ & & & \\
\hline 2 & 100 & $39 \%$ & & & \\
\hline 3 or more & 39 & $15 \%$ & & & \\
\hline \multicolumn{6}{|c|}{ \# of caregivers at home during Circuit-breaker } \\
\hline 1 & 8 & $3 \%$ & & & \\
\hline 2 & 151 & $59 \%$ & & & \\
\hline 3 & 75 & $29 \%$ & & & \\
\hline 4 or more & 24 & $9 \%$ & & & \\
\hline \multicolumn{6}{|l|}{ Domestic helper at home (ref: No) } \\
\hline No & 167 & $65 \%$ & & & \\
\hline Yes & 91 & $35 \%$ & & & \\
\hline COVID-19 Impact & & & 2.01 & 0.61 & 3.00 \\
\hline Parental Stress & & & 2.40 & 0.46 & 2.50 \\
\hline Harsh Parenting & & & 5.70 & 2.15 & 9.00 \\
\hline Parent-child Relationship & & & 11.94 & 2.11 & 8.00 \\
\hline
\end{tabular}

being a parent (Berry and Jones 1995). The PSS scale has been found to have strong psychometric properties, including an internal reliability of Cronbach's $\alpha=.83$ (English version in Berry and Jones 1995), a $\alpha=.89$ in a validation study with a Hong Kong-based sample (Cheung 2000), and strong criterion validity with other parental stress scales such as the 
Parenting Stress Index (Berry and Jones 1995). The PSS is suitable for use with parents of children with and without clinical problems and for fathers and mothers (Berry and Jones 1995).

Parents responded to statements about their parenting over the past weeks on a 4-point Likert scale (responses ranging from $1=$ Never to $4=$ Often). Examples of these statements included: "Caring for my children take more time and energy than I have to give"; "I sometimes worry whether I am doing enough for my child (ren)"; "I feel overwhelmed by the responsibility of being a parent; "I find my children enjoyable"; and "I am happy in my role as a parent." The Cronbach $\alpha$ was .74. A composite score was created by averaging the score across the survey items $(M=2.40, S D=.46)$, with higher scores indicating higher parental stress.

Parenting Outcome Our study assessed two parenting outcomes: harsh parenting behaviors and parent-child relationship closeness.

To provide data on harsh parenting, parents responded to three statements regarding their in disciplinary practices in the weeks since Circuit-breaker had started. These three statements were: (a) "Yelled/screamed at child(ren) more often," (b) "Used harsh words on child(ren) more often," and (c) "Spanked or caned child(ren) more often." These items are similar to those used in large-scale studies in the United States to measure harsh parenting such as the Fragile Families Study (Bendheim-Thoman Center for Research 2018). Parents rated their responses to the statements on a 4-point Likert scale (responses ranging from $1=$ Not true of me at all to $4=$ Very true of me). We summed the scores across the three items to create a measure of harsh parenting. Higher scores indicated a greater increase in the use of harsh parenting in the past weeks $(M=5.70, S D=2.15)$. The Cronbach $\alpha$ was .79.

To provide data on parent-child relationship closeness, parents responded to three statements about their recent relationship with their children: (a) "How close do you feel to your child(ren) in the past few weeks?", "How often have you praised or complimented your child(ren) in the past weeks?", and "How often have you and child(ren) shown love and affection to each other in the past weeks?" These items were constructed for the survey based on the relationship quality (e.g. closeness) dimension in the Child-Parent Relationship Scale (Driscoll and Pianta 2011). Responses used a 5-point Likert scale (responses ranging from $1=$ Never to $5=$ Always). We summed the scores across the three items to create a measure of relationship quality. Higher scores indicated a closer relationship in the past weeks $(M=11.94, S D=2.11)$. The Cronbach $\alpha$ was .74.

Controls Using various sociodemographic variables (Table 1), we controlled for variations in mediational effects that may be attributed to differences in respondents' background characteristics. These included parents' (i.e., mothers' and fathers') relationship to their child(ren), ethnic group (i.e., Chinese, Malay, Indian), age, educational level (i.e., university and non-university level), employment status (i.e., stayhome parents, employed or unemployed), monthly household income, number of caregivers at home during Circuit-breaker, presence of domestic helpers in the household, number of children, and the age of the child(ren).

\section{Analytical Method}

To test our hypotheses, we employed a mediation model analyzed using a structural equation modeling (SEM) framework. The conceptual model is shown in Fig. 1.

We hypothesized that a respondent with higher perceived impact by COVID-19 would report higher levels of parental stress (positive association) through path A. In turn, we hypothesized that higher parental stress would be associated with a higher increase in the use of harsh parenting (positive association; path B). We also hypothesized that higher parental stress would be associated with less parent-child relationship closeness (negative association; path D). Paths $\mathrm{C}$ and $\mathrm{E}$ represent the direct effects of COVID-19 impact on the outcomes. We used the sociodemographic variables listed in Table 1 as controls on the outcomes and the mediator.

The key interest of our analysis was to estimate and interpret the two indirect effect pathways from COVID-19 impact to parenting outcomes through parental stress. We statistically tested for indirect effects using the bootstrap method for mediational analysis as recommended by Hayes (2018). Bootstrapping is used in mediational analyses to generate an empirically derived representation of the sampling distribution of the indirect effect. This empirical representation is then used to construct a confidence interval for the indirect effect. For this study, we generated 10,000 bootstrap samples to produce bootstrap confidence intervals for the indirect effect. If the $99 \%$ confidence limits include zero, the indirect effect test is not significant at the $99 \%$ confidence interval. We did not use the Sorbel test to test for the indirect effect because the Sorbel test requires an assumption of normality for the indirect effect sampling distribution. For small samples like the one employed in the current study, the non-normality of the sampling distribution of the indirect effect is likely to be severe. Normal theory has also been empirically shown to produce inaccurate confidence intervals. Bootstrap confidence intervals can better account for the irregularity of the sampling distribution of the indirect effect and, as a result, produce inferences that are more likely to be accurate than those produced by a normal theory approach. When bootstrapping is used to test an indirect effect, the result is a test with a higher power than that yielded by the normal theory approach.

To interpret the effect size of the indirect effects, we used the partially standardized effect size suggested by Hayes 
(2018). The partially standardized effect size expresses the effect relative to the standard deviation of the outcome rather than in the original metric of the outcome. This has the benefit of giving the effect a context relative to the variability in the outcome. The formula for partially standardized effects as applied to indirect effects is:

$$
\text { Indirect_Effect } \text { partial standardized }=\frac{\text { Indirect_Effect }}{S D \text { of outcome }}
$$

For instance, if a partially standardized indirect effect is .50 , this means that when the independent variable increases by one unit, the outcome changes by .50 of a standard deviation as a result of the effect of the independent variable on the outcome through the mediating effects of the mediator.

We report both unstandardized and standardized path coefficients and the bootstrap confidence intervals at the $99 \%$ level. Missing data analysis using Little's test (Li 2013) indicated that missing data $(n=6)$ were missing completely at random $\left(\chi^{2}[1,264]=.003, p=.95\right)$. All mediation analyses were conducted using Mplus version 8.4.

\section{Results}

Table 1 provides the sociodemographic characteristics of our sample. Most parents were Chinese (82\%), which somewhat reflected the demographic proportions of the Singapore population in 2019 (i.e., 74.4\% Chinese, 13.4\% Malay, 9\% Indian, and 3.2\% Others; Department of Statistics Singapore [DOS], 2019). Most respondents who completed the surveys were mothers (64\%), most were 36 to 40 years old (32\%), and most were highly educated, with
$85 \%$ having at least a university degree. Most parents were also employed either at full employment $(73 \%)$ or in temporary or casual employment (6\%). Fifty-eight percent of the parents earned a monthly household income more than $\mathrm{S} \$ 8000$ (about USD $\$ 5600$ ) per month. With the median income of a resident household in Singapore in 2019 at about S\$7981 (DOS 2020), this sample consisted mostly of families with financial income greater than 50\% of all households in Singapore. Among parents' youngest children, most were 0 to 1 year in age (24\%); $63 \%$ of parents had at least one child whose age was from 0 to 6 years. $46 \%$ of parents had only one child of age 12 or younger. $59 \%$ of respondents had two caregivers (including the respondent) and 38\% had three or more caregivers in the household during the Circuit-breaker. 35\% of parents reported having a domestic helper at home.

Correlations between study variables are shown in Table 2 . Bivariate correlations indicate that higher parental stress is significantly associated with higher harsh parenting and poorer relationship. Younger age of parents and mothers were significantly associated with higher parental stress. The number of children, number of caregivers at home during the Circuit-breaker, domestic helper, income, employment, and education of respondents were not significantly associated with parental stress.

Results from our mediation analysis indicated that the impact of COVID-19 indirectly influenced both parenting outcomes (i.e., harsh parenting and parent-child relationship closeness) through its effect on parenting stress. The directions of the pathways all supported our hypotheses (Fig. 1). As shown in Fig. 2 and Table 3, parents who were more impacted by COVID-19 experienced more parenting stress $(b=.22, p<.001)$ than those who felt they were less impacted by COVID-19, and parents who experienced more parenting stress indicated that they had used more harsh parenting $(b=$

Table 2 Correlation Table for Study Variables and Covariates

\begin{tabular}{|c|c|c|c|c|c|c|c|c|c|c|c|c|c|c|c|}
\hline & Variable & 1 & 2 & 3 & 4 & 5 & 6 & 7 & 8 & 9 & 10 & 11 & 12 & 13 & 14 \\
\hline 1. & Parental Stress & - & & & & & & & & & & & & & \\
\hline 2. & Harsh Parenting & $0.56^{*}$ & - & & & & & & & & & & & & \\
\hline 3. & Parent-child Relationship & $-0.25^{*}$ & $-0.30^{*}$ & - & & & & & & & & & & & \\
\hline 4. & COVID-19 Impact & $0.29 *$ & $0.20 *$ & -0.05 & - & & & & & & & & & & \\
\hline 5. & Parent Age & $-0.13^{*}$ & -0.04 & $-0.31^{*}$ & -0.05 & - & & & & & & & & & \\
\hline 6. & Parent Sex & $0.18 *$ & 0.02 & 0.03 & 0.04 & -0.08 & - & & & & & & & & \\
\hline 7. & \# Children & 0.06 & $0.15^{*}$ & -0.03 & 0.05 & -0.07 & -0.03 & - & & & & & & & \\
\hline 8. & Child Age & -0.09 & $-0.13^{*}$ & $-0.22^{*}$ & -0.05 & $0.62 *$ & 0.01 & $-0.25^{*}$ & - & & & & & & \\
\hline 9. & Domestic Helper & -0.09 & -0.06 & 0.08 & $-0.12 *$ & -0.04 & 0.05 & $-0.26^{*}$ & 0.07 & - & & & & & \\
\hline 10. & Income & 0.01 & 0.04 & $-0.13^{*}$ & $-0.23 *$ & 0.10 & 0.00 & -0.02 & -0.02 & $-0.17 *$ & - & & & & \\
\hline 11. & Parent Employment & -0.08 & -0.01 & 0.09 & $0.13 *$ & 0.07 & -0.11 & 0.04 & -0.02 & 0.02 & -0.12 & - & & & \\
\hline 12. & Race & -0.06 & 0.03 & $-0.21^{*}$ & -0.05 & $0.24 *$ & -0.10 & 0.07 & 0.04 & 0.00 & $0.18^{*}$ & 0.05 & - & & \\
\hline 13. & Parent Education & -0.02 & 0.04 & $-0.13^{*}$ & -0.05 & $0.14 *$ & -0.02 & 0.00 & -0.02 & $-0.19 *$ & $0.49 *$ & 0.01 & $0.18 *$ & - & \\
\hline 14. & \# Caregiver & 0.19 & 0.08 & -0.07 & 0.12 & -0.04 & -0.04 & 0.14 & -0.11 & $-0.65 *$ & $0.15 *$ & 0.00 & -0.07 & 0.10 & - \\
\hline
\end{tabular}

Note: $* p<.05$ 
Fig. 2 Results of Path Analysis Showing Unstandardized Path Coefficients (Standardized Coefficients in Parentheses) After Controlling for Demographics. Note: $* * * p<.001$

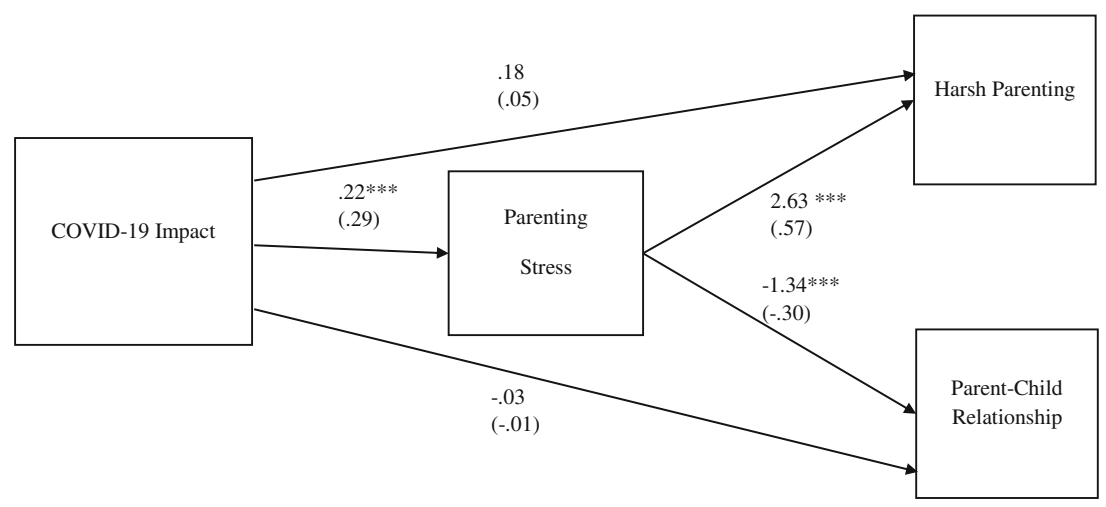

2.63, $p<.001)$ and felt less close with their children $(b=$ $-1.34, p<.001)$ in the past weeks. For the harsh parenting outcome, a bootstrap $99 \%$ confidence interval for the indirect effect $(b=0.58$ ) based on 10,000 bootstrap samples was entirely above zero ( 0.25 to 0.94$)$. For the parent-child relationship outcome, the bootstrap $99 \%$ confidence interval for the indirect effect $(b=-.30)$ was entirely below zero $(-.59$ to $-.11)$. There was no evidence that parents' perceived impact of COVID-19 influenced harsh parenting $(b=.18, p=.38)$ or parent-child relationships $(b=-.03, p=.90)$ independent of its effect on parenting stress.

The partial standardized effects are shown in Table 3. The partial standardized effect of the indirect effect for harsh parenting is .27 . This means that for two parents who differ by one unit in how they perceive the impact of COVID-19, they will differ by .27 standard deviations in their use of harsh parenting as a result of the impact of COVID-19 on parental stress. For parent-child relationship closeness, the partial standardized effect is -.14 , around half the magnitude of the indirect effect for harsh parenting.

\section{Discussion}

To reduce the transmission of COVID-19, the Singaporean government has been implementing Circuit-breaker for almost two months, from April 2020 to May 2020. The closures of schools, childcare services, and workplaces has meant that many parents are working remotely from home and caring for their children without respite, thus facing significant stress associated with the role of parenting. For some parents, the loss of a job or reduced wages further exacerbated this stress. In the current study, informed by the Parental Stress Model, we hypothesized that parents who reported that they experienced a greater impact from COVID-19 would also report higher levels of parental stress and higher parental stress is associated with negative parenting behaviors. Lastly, we hypothesized that the effects of the perceived impact of COVID19 on parenting outcomes would both be mediated through parental stress.

All our hypotheses were supported by the results of our study. Using the CIQ scale, we collected data on parents'

Table 3 Total, Direct, and Indirect Effects for Mediation Model

\begin{tabular}{|c|c|c|c|c|c|c|}
\hline & \multicolumn{3}{|c|}{ Outcome 1: Harsh Parenting } & \multicolumn{3}{|c|}{ Outcome 2: Parent-child Relationship } \\
\hline & Unstandardized $\beta$ & LB 99\% CI & $\mathrm{RB} 99 \% \mathrm{CI}$ & Unstandardized $\beta$ & LB 99\% CI & RB $99 \% \mathrm{CI}$ \\
\hline \multicolumn{7}{|l|}{ Total, Direct, Indirect Effects } \\
\hline Total Effect (COVID-19 $\rightarrow$ Outcome) & $0.76^{* *}$ & 0.10 & 1.38 & -0.32 & -0.86 & 0.23 \\
\hline Direct Effect (COVID-19 $\rightarrow$ Outcome) & 0.18 & -0.34 & 0.72 & -0.03 & -0.56 & 0.52 \\
\hline $\begin{array}{l}\text { Indirect Effect }(\text { COVID-19 } \rightarrow \text { Parenting } \\
\quad \text { Stress } \rightarrow \text { Outcome })\end{array}$ & $0.58 * *$ & 0.25 & 0.94 & $-0.30 * *$ & -0.59 & -0.11 \\
\hline \multicolumn{7}{|l|}{ Effect Size } \\
\hline Partial Standardized Effect of the Total Effect & 0.35 & - & - & -0.15 & - & - \\
\hline Partial Standardized Effect of the Direct Effect & 0.08 & - & - & -0.01 & - & - \\
\hline Partial Standardized Effect of the Indirect Effect & 0.27 & - & - & -0.14 & - & - \\
\hline
\end{tabular}

Note

LB Boot-strapped $99 \%$ CI is left-bound $99 \%$ confidence interval; RB is right-bound

*** Statistically significant at $<.01$ 
perceptions of how COVID-19 had impacted their finances and employment, their access to resources, and their psychological health. Parents who reported a greater impact of COVID-19 also reported higher levels of parental stress. Higher parental stress was associated with increased use of harsh parenting and less parent-child relationship closeness. The key finding of the study is that levels of parental stress mediated the impact of COVID-19 on harsh parenting and parent-child relationship closeness.

In the Parental Stress Model (Abidin 1992), stress arises as a result of the perception of environmental stressors or demands associated with the parenting role. Similarly, DeaterDeckard (1998) also discussed the effects of stressful life experiences and circumstances on parental stress. Our study shows that mitigating the perceived impact of COVID-19 and Circuit-breaker measure on parents can help to reduce their level of parenting-related stress.

The Singaporean government has implemented several initiatives to address the economic impact of COVID-19. To mitigate the financial impact for workers, the government included measures in their Resilience Budget to improve job support for workers and companies in economic sectors that had been severely affected by the COVID-19 pandemic. Monthly cash grants were given to workers who lost their job during the pandemic. Cash payouts of at least $\$ 300$ were also given to all adult Singaporeans to cope with financial uncertainties (Cheng 2020). The effectiveness of these measures in mitigating the financial impact on parents has not been evaluated. However, we expect that any efforts to mitigate COVID-19's negative impacts would have downstream protective effects in reducing the level of stress experienced by parents, which would in turn increase their use of positive parenting behaviors (Shulruf et al. 2009). Government efforts to mitigate the economic impact of the pandemic will be needed long after the pandemic is controlled such as measures to help financially-distressed businesses (e.g., financing support, tax and other temporary relief measures) so that jobs can be saved.

Supporting parents' psychological health is also important - both for parents and for their children. Psychological services, counseling, and social work services are vital during lock-downs or stay-home orders. Although the Singaporean government had initially classified psychological and social work services provided in non-healthcare sectors as "non-essential services," they were subsequently re-classified as "essential" due to the extension of Circuit-breaker policies (CNA 2020d). Providing psychological, counseling, and social work services through telehealth rather than face-to-face sessions will be especially necessary, as parents may not be able to leave their homes due to their caregiving responsibilities. Even though lock-down or stay-home orders are effective public health measures to reduce virus transmission rates, our study shows that targeted support and services are needed to mitigate the psychological impact that these measures can have on parents as well as children (Fontanesi et al. 2020).
Parenting under typical conditions is already difficult, as many parents struggle to balance work and parenting duties. During lockdowns when families remain at home for prolonged periods of time, parents must perform multiple roles with fewer resources and less support than they previously received from schools, churches, neighborhoods, and other family members. Our study's key finding is that higher parenting stress as a result of COVID-19 and the Circuitbreaker measure is associated with more negative parenting outcomes. We found that parenting stress was related to higher incidence of harsh parenting (i.e., caning, spanking, use of harsh words, and yelling) and less relationship closeness between parents and children. The effect size of the association between parenting stress and harsh parenting was almost twice the magnitude of the association between parenting stress and parent-child relationship closeness.

Harsh parenting practices are characterized by high levels of coercive control, aggression, and negative emotionality, and several studies have affirmed its negative associations with subsequent internalizing and externalizing symptoms among children who experience harsh parenting (Pinquart 2017). Additionally, given the associations between harsh parenting and child abuse (Chng et al. 2018), we are concerned that parents who are experiencing high levels of parental stress may be more likely to engage in child abuse - an especially troubling prospect given the scope of the difficulties experienced by parents due to COVID-19.

Parenting interventions such as Parent-Child Interaction Therapy (PCIT) and Triple P are effective in increasing parents' use of non-punitive disciplinary methods, helping them to cope with parental stress, and improving parent-child relationships (Lanier et al. 2011; Thomas and Zimmer-Gembeck 2007). For instance, Triple-P aims to promote parental competence through five core positive parenting principles that include the use of assertive disciplines and taking care of oneself as a parent (Sanders 1999). These principles translate into teaching specific skills that promotes parents' use of non-punitive disciplinary methods and healthy communication skills as well as promoting the parents' capacity for self-regulation and self-care (e.g., learning specific emotional coping strategies to manage parental stress; Sanders 1999). Both interventions also have foundations in social learning theory, which focuses on improving the interactions between the parent and the child. Their focus on dyadic interactions is important given that prior studies have found a transactional relationship between harsh parenting and children's behaviors. For instance, MacKenzie et al. (2015) found that an initial incident of spanking had lasting effects on the reciprocal relationship between parents' subsequent frequency of using spanking and the child's behaviors. Because Triple $P$ programming has been previously implemented in Singapore (Koh 2016), it would likely offer an expedient resource to parents while Circuit-breaker measures are in place by helping them cope 
with parental stress and encouraging them to use more ageappropriate disciplinary methods with their children.

However, implementing therapist-led or office-based behavioral parenting interventions may be challenging when parents are not able to leave their homes. For this reason, policymakers should also consider implementing online self-directed (SD) parenting interventions, which provide parents with the materials necessary to teach behavioral strategies to themselves at home (Tarver et al. 2014). SD interventions come in different formats (e.g. manual, internet, video) and offer different levels of therapist support to guide the parent through the intervention. One metaanalysis (Tarver et al. 2014) found that SD interventions effectively reduced children's externalizing behaviors, improved parenting behaviors, and reduced parental stress. SD interventions also did not significantly differ from therapist-led or office-based parenting interventions in reducing externalizing behaviors. Examples of SD interventions that used Triple $\mathrm{P}$ can be found in Tarver et al. (2014) and examples of those that used PCIT in Berkovits et al. (2010).

\section{Limitations}

This study's findings should be considered in light of its limitations. First, the sample in this study included respondents who are married, mostly Chinese, parents in their $30 \mathrm{~s}$ to $40 \mathrm{~s}$, financially well-to-do, and highly educated. Thus, the findings in this study may not be valid for families with lesser financial resources, or for different family structures (e.g., single-parent families), or for other ethnic groups in Singapore. Second, this study does not differentiate between the effects of COVID-19 pandemic and Circuit-breaker policies because our data collection began when Circuit-breaker policies had already been implemented. The impact of COVID-19 as conceptualized in this study would include the effects of Circuit-breaker measures. Third, the CIQ questionnaire used to measure the impact of COVID-19, while relevant to the experiences of respondents in Singapore, may not have captured all the types of impact salient in the context of Singapore. For instance, even though researchers such as Weems et al. (2020) have discussed the disruptions that social distancing measures have caused to people's social ties and access to social support, the CIQ questionnaire does not measure these effects. This detail is notable as previous studies have shown that low social support is a risk factor for higher parental stress levels (Ostberg \& Hagekull 2000) - a finding relevant to the present study. Fourth, we did not use a validated scale to measure parent-child relationship construct though we constructed items based on the Child-Parent Relationship Scale. Fifth, since parents are the sole reporters for all study variables and self-report survey was the only data-collection method used, there is a possibility of shared-method bias. Future studies could use different reporters and methods of reporting to validate the findings of this study. Sixth, due to our research design, we could not account for parental stress before Circuit-breaker that may affect later functioning.

Although our study found evidence that parental stress mediates parents' perceived effects of COVID-19 on their parenting outcomes, we do not claim that this constitutes proof of causation purely based on statistical methods (Hayes 2018). Rather, our arguments for causality are based on earlier models' theoretical conceptualizations of parental stress (Abidin 1992; DeaterDeckard 1998) and on the fact that such models (e.g., the Parental Stress Model) have identified parental stress as a key determinant of dysfunctional parenting (Abidin 1992; Bornstein et al. 2018). Our study certainly cannot explain the full matrix of associations between the impact of COVID-19, parental stress, and parenting outcomes. We therefore suggest other possible mediators and alternative pathways below.

First, other factors such as marital stress, mental health, workfamily balance, or family functioning may also have mediated the effects of COVID-19 on parental stress (Brown et al. 2020; Chung et al. 2020a). Although parental stress is conceptually distinct from other forms of stress, it is often related to other stressors that parents encounter in their various roles, such as caregiver, worker, spouse, and others. Second, we did not explore the direct impact of COVID-19 on children or the possible ways that children's behaviors could influence parents (i.e., "child-to-parent" effects discussed in Serbin et al., 2015, p.969). Children certainly are not impervious to the impacts of COVID-19. Physical isolation and school closures for prolonged periods can have many effects, including anxieties and uncertainties that may lead to externalizing and internalizing behaviors (Romero et al. 2020). Third, the parenting of our survey respondents' spouses likely also influenced these respondents' parenting behaviors (Chung et al. 2020b). Without considering the joint effects of both parents, this study may not fully capture the most salient mediators of parenting, in or out of pandemic contexts.

\section{Implications for Practice}

Despite the limitations, our study provides timely insights into potential consequences of COVID-19-induced parental stress. Many researchers are concerned with the effects of lockdowns on parents and potential family violence. Our findings offer evidence of the role of parental stress in shaping parenting behaviors and parent-child relationships, and suggest that reducing parental stress may be an impactful means of supporting family wellbeing during the COVID-19 pandemic.

Governments must play a key role in mitigating the impact of COVID-19 on families. As discussed above, cash payouts and job support measures during and after the pandemic will be important to help families cope financially and to recover from job losses and wage reductions. Given the demonstrable impact of COVID-19 on many parents' psychological health, we also suggest that mental health, social work, and counseling services be designated as or continue to be designated as 
essential services in the current pandemic and in any future pandemics. These services should also consider developing their capacity for providing telehealth services and remote counseling sessions. Given the confinement of parents to their homes, parenting interventions such as PCIT and Triple P could also be delivered in a self-directed format in which parents can teach themselves to use age-appropriate and positive parenting skills while complying with social distancing and stay-at-home regulations.

\section{References}

Abidin, R. R. (1992). The determinants of parenting behavior. Journal of Clinical Child Psychology, 21(4), 407-412. https://doi.org/10.1207/ s15374424jccp2104_12.

Agrawal, N. (2020). The Coronavirus Could Cause a Child Abuse Epidemic. The New York Times. https:/www.nytimes.com/2020/ 04/07/opinion/coronavirus-child-abuse.html

Azhari, A., Leck, W. Q., Gabrieli, G., Bizzego, A., Rigo, P., Setoh, P., Bornstein, M. H., \& Esposito, G. (2019). Parenting stress undermines mother-child brain-to-brain synchrony: A Hyperscanning study. Scientific Reports, 9(1), 1-9. https://doi.org/10.1038/ s41598-019-47810-4.

Bendheim-Thoman Center for Research. (2018). User's guide for the fragile families and child wellbeing study public data. BendheimThoman Center for Research. https://fragilefamilies.princeton.edu/ sites/fragilefamilies/files/year_3 guide.pdf

Berkovits, M. D., O’Brien, K. A., Carter, C. G., \& Eyberg, S. M. (2010). Early identification and intervention for behavior problems in primary care: A comparison of two abbreviated versions of parentchild interaction therapy. Behavior Therapy, 41(3), 375-387. https://doi.org/10.1016/j.beth.2009.11.002.

Berry, J. O., \& Jones, W. H. (1995). The parental stress scale: Initial psychometric evidence. Journal of Social and Personal Relationships, 12(3), 463-472. https://doi.org/10.1177/ 0265407595123009.

Bornstein, M. H., Putnick, D. L., \& Suwalsky, J. T. D. (2018). Parenting cognitions $\rightarrow$ parenting practices $\rightarrow$ child adjustment? The standard model. Development and Psychopathology, 30(2), 399-416. https:// doi.org/10.1017/S0954579417000931.

Brooks, S. K., Webster, R. K., Smith, L. E., Woodland, L., Wessely, S., Greenberg, N., \& Rubin, G. J. (2020). The psychological impact of quarantine and how to reduce it: Rapid review of the evidence. The Lancet, 395(10227), 912-920. https://doi.org/10.1016/S01406736(20)30460-8.

Brooks-Gunn, J., Schneider, W., \& Waldfogel, J. (2013). The great recession and the risk for child maltreatment. Child Abuse \& Neglect, 37(10), 721-729. https://doi.org/10.1016/j.chiabu.2013.08.004.

Brown, S. M., Doom, J., Watamura, S., Lechuga-Pena, S., \& Koppels, T. (2020). Stress and Parenting during the Global COVID-19 Pandemic [preprint]. PsyArXiv. https://doi.org/10.31234/osf.io/ ucezm.

Campbell, A. M. (2020). An increasing risk of family violence during the Covid-19 pandemic: Strengthening community collaborations to save lives. Forensic Science International: Reports, 2, 100089. https:// doi.org/10.1016/j.fsir.2020.100089.

Chang, L., Schwartz, D., Dodge, K. A., \& McBride-Chang, C. (2003). Harsh parenting in relation to child emotion regulation and aggression. Journal of Family Psychology, 17(4), 598-606. https://doi.org/ 10.1037/0893-3200.17.4.598.
CNA. (2020a). MSF keeping "close watch" on domestic abuse cases as more reach out for help over circuit breaker period. Channel News Asia. https://www.channelnewsasia.com/news/singapore/covid-19msf-domestic-abuse-violence-cases-circuit-breaker-12671330.

CNA. (2020b). PM Lee's address on enhanced measures to deal with COVID-19 situation in Singapore. Channel News Asia. https:// www.channelnewsasia.com/news/singapore/coronavirus-covid-19lee-hsien-loong-update-address-nation-tv-12606328.

CNA. (2020c). Singapore to exit circuit breaker on Jun 1, visiting of parents, places of worship allowed with restrictions. CNA. https:// www.channelnewsasia.com/news/singapore/singapore-exit-circuitbreaker-jun-1-visit-parents-worship-12749222.

CNA. (2020d). Psychology, podiatry and other allied health services reclassified as essential under COVID-19 circuit breaker: MOH. CNA. https://www.channelnewsasia.com/news/singapore/coronaviruscovid-19-health-essential-services-therapy-rehab-12683960.

Cheng, I. (2020). COVID-19 budget: What you need to know about the resilience budget measures. CNA. https://www.channelnewsasia. com/news/singapore/covid19-coronavirus-budget-5-things-hengswee-keat-12579156.

Cheung, S.-K. (2000). Psychometric properties of the Chinese version of the parental stress scale. Psychologia: An International Journal of Psychology in the Orient, 43, 253-261.

Chng, G. S., Li, D., Chu, C. M., Ong, T., \& Lim, F. (2018). Family profiles of maltreated children in Singapore: A latent class analysis. Child Abuse \& Neglect, 79, 465-475. https://doi.org/10.1016/j. chiabu.2018.02.029.

Chung, G., Phillips, J., Jensen, T. M., \& Lanier, P. (2020a). Parental involvement and adolescents' academic achievement: Latent profiles of mother and father warmth as a moderating influence. Family Process, 59(2), 772-788. https://doi.org/10.1111/famp. 12450.

Chung, G, Chan, X.W, Lanier, P., \& Ju, P. W. Y. (2020b). Associations Between Work-Family Balance, Parenting Stress, and Marital Conflicts During COVID-19 Pandemic in Singapore [Preprint]. https://doi.org/10.31219/osf.io/nz9s8.

Cluver, L., Lachman, J. M., Sherr, L., Wessels, I., Krug, E., Rakotomalala, S., Blight, S., Hillis, S., Bachman, G., Green, O., Butchart, A., Tomlinson, M., Ward, C. L., Doubt, J., \& McDonald, K. (2020). Parenting in a time of COVID-19. The Lancet, 395(10231), e64. https://doi.org/10.1016/S0140-6736(20) 30736-4.

Conway, L. G., Woodard, S. R., \& Zubrod, A. (2020). Social Psychological Measurements of COVID-19: Coronavirus Perceived Threat, Government Response, Impacts, and Experiences Questionnaires. PsyArXiv. https://doi.org/10.31234/ osf.io/z2x9a.

Coyne, L. W., Gould, E. R., Grimaldi, M., Wilson, K. G., Baffuto, G., \& Biglan, A. (2020). First Things First: Parent Psychological Flexibility and Self-Compassion During COVID-19 [preprint]. Open Science framework. https://doi.org/10.31219/osf.io/pyge2.

Crnic, K. A., Gaze, C., \& Hoffman, C. (2005). Cumulative parenting stress across the preschool period: Relations to maternal parenting and child behaviour at age 5. Infant and Child Development, 14(2), 117-132. https://doi.org/10.1002/icd.384.

Deater-Deckard, K. (1998). Parenting stress and child adjustment: Some old hypotheses and new questions. Clinical Psychology: Science and Practice, 5(3), 314-332. https://doi.org/10.1111/j.1468-2850. 1998.tb00152.x.

DOS. (2019). Population trends, 2019. Ministry of Trade \& Industry.

DOS. (2020). Average and Median Monthly Household Income from Work (Including Employer CPF Contributions) Among Resident and Resident Employed Households, 2000-2019.

Driscoll, K. \& Pianta, R. C. (2011). Mothers' and fathers' perceptions of conflict and closeness in parent-child relationships during early 
childhood. Journal of early childhood and infant psychology, 7, 124. ProQuest Central.

Eltanamly, H., Leijten, P., Jak, S., \& Overbeek, G. (2019). Parenting in times of War: A Meta-Analysis and Qualitative Synthesis of War Exposure, Parenting, and Child Adjustment. Trauma, Violence, \& Abuse. https://doi.org/10.1177/1524838019833001.

Fontanesi, L., Marchetti, D., Mazza, C., Di Giandomenico, S., Roma, P., \& Verrocchio, M. C. (2020). The effect of the COVID-19 lockdown on parents: A call to adopt urgent measures. Psychological Trauma: Theory, Research, Practice, and Policy, 12(S1), S79-S81.

Gershoff, E. T., Sattler, K. M. P., \& Ansari, A. (2018). Strengthening causal estimates for links between spanking and Children's externalizing behavior problems. Psychological Science, 29(1), 110-120. https://doi.org/10.1177/0956797617729816.

Hayes, A. F. (2018). Introduction to mediation, moderation, and conditional process analysis (2nd ed.). Guilford Press.

Holly, L. E., Fenley, A. R., Kritikos, T. K., Merson, R. A., Abidin, R. R., \& Langer, D. A. (2019). Evidence-Base update for parenting stress measures in clinical samples. Journal of Clinical Child \& Adolescent Psychology, 48(5), 685-705.

ILO. (2020). Almost 25 million jobs could be lost worldwide as a result of COVID-19, says ILO [Press release]. http://www.ilo.org/global/ about-the-ilo/newsroom/news/WCMS 738742/lang\%2D\%2Den/ index.htm.

Jackson, A. P., \& Choi, J.-K. (2018). Parenting stress, harsh parenting, and Children's behavior. Journal of Family Medicine \& Community Health, 5(3), 10 .

Koh, X. H. (2016). Parenting scheme helps to lower stress. The Straits Times. https://www.straitstimes.com/singapore/parenting-schemehelps-to-lower-stress.

Lanier, P., Kohl, P. L., Benz, J., Swinger, D., Moussette, P., \& Drake, B. (2011). Parent-child interaction therapy in a community setting: Examining outcomes, attrition, and treatment setting. Research on Social Work Practice, 1(6), 689-698. https://doi.org/10.1177/ 1049731511406551

Lazarus, R., \& Folkman, S. (1984). Stress, appraisal, and coping. Springer.

Lee, S. J., Grogan-Kaylor, A., \& Berger, L. M. (2014). Parental spanking of 1-year-old children and subsequent child protective services involvement. Child Abuse and Neglect, 38(5), 875-883. https://doi. org/10.1016/j.chiabu.2014.01.018.

Li, C. (2013). Little's test of missing completely at random. Stata Journal, 13(4), 795-809.

Liu, L., \& Wang, M. (2015). Parenting stress and harsh discipline in China: The moderating roles of marital satisfaction and parent gender. Child Abuse \& Neglect, 43, 73-82.

Lutz, W. J., Hock, E., \& Kang, M. J. (2007). Children's communication about distressing events: The role of emotional openness and psychological attributes of family members. American Journal of Orthopsychiatry, 77(1), 86-94. https://doi.org/10.1037/0002-9432. 77.1.86.

MacKenzie, M. J., Nicklas, E., Brooks-Gunn, J., \& Waldfogel, J. (2015). Spanking and Children's externalizing behavior across the first decade of life: Evidence for transactional processes. Journal of Youth and Adolescence, 44(3), 658-669. https://doi.org/10.1007/s10964014-0114-y.

Mohan, M. (2020). Circuit breaker extended until Jun 1 as Singapore aims to bring down community cases 'decisively': PM Lee. Channel News Asia. https://www.channelnewsasia.com/news/ singapore/covid-19-circuit-breaker-extended-june-pm-lee-speechapr-21-12662054.

National Academies of Sciences, E., and Medicine. (2016). Parenting Matters: Supporting Parents of Children Ages $0-8$. The National Academies Press. https://doi.org/10.17226/21868.

Ostberg, M., \& Hagekull, B. (2000). A structural modeling approach to understanding parenting stress. Journal of Clinical Child
Psychology,29(4), 615. https://doi.org/10.1207/ S15374424JCCP2904 13.

Pinquart, M. (2017). Associations of parenting dimensions and styles with externalizing problems of children and adolescents: An updated meta-analysis. Developmental Psychology, 53(5), 873-932. https://doi.org/10.1037/dev0000295.

Romero, E., López-Romero, L., Domínguez-Álvarez, B., Villar, P., \& Gómez-Fraguela, J. A. (2020). Testing the effects of COVID-19 confinement in Spanish children: The role of parents' distress, emotional problems and specific parenting [preprint]. PsyArXiv. https:// doi.org/10.31234/osf.io/spxtw.

Salloum, A., \& Lewis, M. (2010). An exploratory study of African American parent - Child coping strategies post- hurricane Katrina. Traumatology, 16(1), 31-41. https://doi.org/10.1177/ 1534765609348240.

Sanders, M. R. (1999). Triple P-positive parenting program: Towards an empirically validated multilevel parenting and family support strategy for the prevention of behavior and emotional problems in children. Clinical Child and Family Psychology Review, 2(2), 71-90.

Shulruf, B., O'Loughlin, C., \& Tolley, H. (2009). Parenting education and support policies and their consequences in selected OECD countries. Children and Youth Services Review, 31(5), 526-532.

Sim, T. N., \& Ong, L. P. (2005). Parent physical punishment and child aggression in a Singapore Chinese preschool sample. Journal of Marriage and Family, 67(1), 85-99.

Singapore Social, Lifestyle and Infection Networks Group. (2020 23). Impact on work patterns and wage. https://nussling.github.io/ 2020-04-23-covid19 circuitbreaker workpatterns/.

Tang, S. (2020). Singapore will enter a recession this year, 'significant uncertainty' over duration and intensity: MAS. CNA. https://www. channelnewsasia.com/news/singapore/covid-19-economysingapore-will-enter-recession-2020-mas-review-12683096.

Tarver, J., Daley, D., Lockwood, J., \& Sayal, K. (2014). Are self-directed parenting interventions sufficient for externalising behaviour problems in childhood? A systematic review and meta-analysis. European Child \& Adolescent Psychiatry, 23(12), 1123-1137.

The New York Times. (2020, June 5). Coronavirus Map: Tracking the Global Outbreak. The New York Times. https://www.nytimes.com/ interactive/2020/world/coronavirus-maps.html.

Thomas, R., \& Zimmer-Gembeck, M. J. (2007). Behavioral outcomes of parent-child interaction therapy and triple $\mathrm{P}$-Positive parenting program: A review and meta-analysis. Journal of Abnormal Child Psychology, 35(3), 475-495. https://doi.org/10.1007/s10802-0079104-9.

Tong, C. K., Elliott, J. M., \& Tan, P. M. E. H. (1996). Public perceptions of child abuse and neglect in Singapore. Singapore Children's Society.

Weems, C. F., Carrion, V. G., Mccurdy, B. H., \& Scozzafava, M. D. (2020). Increased Risk of Suicide Due to Economic and Social Impacts of Social Distancing Measures to Address the Covid-19 Pandemic: A Forecast. https://doi.org/10.13140/RG.2.2.21601. 45926.

WHO. (2020). Statement on the second meeting of the International Health Regulations (2005) Emergency Committee regarding the outbreak of novel coronavirus (2019-nCoV).

Yip, C., \& Smalley, R. (2020). Home-based learning blues: Life in a rental flat during the COVID-19 circuit breaker. CNA. https:// www.channelnewsasia.com/news/cnainsider/home-based-learningrental-flat-low-income-covid19-12685142.

Zhuo, T., \& Tai, J. (2020). Coronavirus: Families scraping by in tougher spot now. The Straits Times. https://www.straitstimes.com/ singapore/families-scraping-by-in-tougher-spot-now.

Publisher's Note Springer Nature remains neutral with regard to jurisdictional claims in published maps and institutional affiliations. 